\title{
EL PINTOR ANTONIO MARÍA ESQUIVEL Y SU ENTORNO FAMILIAR: A PROPÓSITO DE DOS RETRATOS INÉDITOS DE SU ESPOSA
}

\author{
THE PAINTER ANTONIO MARÍA ESQUIVEL \\ AND HIS FAMILY ENVIRONMENT: A PURPOSE \\ OF TWO UNKNOWN PORTRAITS OF HIS WIFE
}

\author{
Gerardo Pérez Calero \\ Universidad de Sevilla. España \\ ORCID: 0000-0001-7554-5070 \\ gcalero@us.es
}

\begin{abstract}
En este trabajo se estudian dos retratos desconocidos que ejecutó el pintor Antonio María Esquivel de su mujer Antonia Rivas.

Palabras claves: pintura española; siglo XIX; Sevilla; Antonio María Esquivel; Antonia Rivas.

Two unknown portraits executed by the painter Antonio María Esquivel of his wife Antonia Rivas are studied in this paper.

Keywords: Spanish painting; $19^{\text {th }}$ century; Seville; Antonio María Esquivel: Antonia Rivas.
\end{abstract}

La apasionante y hasta novelesca por romántica biografía del pintor hispalense Antonio María Esquivel y Suárez de Urbina (Sevilla, 8 de mayo de 1806-Madrid, 9 de abril de 1857) está plagada de acontecimientos e hitos de diverso tipo en los que se patentizan su vitalismo, apasionado carácter y probado patriotismo. Sin embargo, nos interesa ahora subrayar su faceta familiar y social íntimamente relacionada con la artística, ya que a tal plenitud vital corresponde no menor fecundidad y vigor creativo.

Hombre sencillo aunque de origen hidalgo, pues sus apellidos figuraron entre los más destacados de la milicia desde los tiempos de la España imperial, empero familiarmente venido a menos, ya que su padre, simple pero heroico capitán de Caballería muerto en la batalla de Bailén, le dejó huérfano con dos años al 
cuidado de su madre, mujer de fuerte carácter. Ella le procuró con muchos esfuerzos y medios limitados una esmerada educación acrecentada por sus estudios en el prestigioso Colegio dominico de Santo Tomás recién reabierto en 1815 tras la francesada, donde cursó Humanidades al objeto de hacerse escritor, que sin embargo tornó por el aprendizaje de las Bellas Artes, si acaso fuere por sus ascendientes familiares del mismo apellido como maestros de la pintura renacentista y barroca ${ }^{1}$. En este último campo artístico, Antonio María empezaría pronto a destacar por sus innatas dotes creativas y constante laboriosidad ${ }^{2}$.

Desde joven se rodeó Esquivel, hombre de trato afable y buen conversador, de amigos y compañeros artistas como él en el ejercicio de la pintura; tal es el caso en Sevilla, entre otros y sobre todo, de José María Domínguez Bécquer, el más popular y querido de los pintores del momento que, aunque solo un año mayor que él fue su profesor y con el tiempo también testigo de su boda con la bella paisana Antonia Rivas Bravo, joven dama de buena familia y trato gentil, ceremonia que se celebraría, no sin antes cumplir sus obligaciones militares como buen patriota y aventurero romántico, a su vuelta de las campañas contra los ejércitos invasores absolutistas de los Cien Mil Hijos de San Luis ${ }^{3}$.

En efecto, en 1827, contando Antonio María veintidós años de edad y ella uno menos, contrajeron matrimonio en la entonces parroquia de San Martín, collación en la que Antonia residía, mientras él pertenecía a la de San Juan de la Palma ${ }^{4}$. Establecieron momentáneamente su domicilio en Sevilla en la que vivieron tres años más hasta su marcha a Madrid. En este ínterin, al año siguiente de la boda, el maestro retrató a su joven desposada a modo de presente y también como seña premonitoria de una fecunda descendencia de tres hijos que llegaría a darle. También la volvió a retratar apenas tres años después, tras haber nacido su primogénito Carlos María en 1830, y avecindados en Madrid al año siguiente.

Mas, antes de analizar las dos obras y vincularlas al espacio y al tiempo correspondientes, objeto principal de este trabajo, es obligado hacer una breve referencia a su autor como retratista, género en el que descolló por encima de otros y al que dedicó no pocos esfuerzos, tanto por su condición de pintor de fama

${ }^{1}$ DE LA BANDA Y VARGAS, Antonio: Antonio María Esquivel. Sevilla, 2002, p. 30.

2 PÉREZ CALERO, Gerardo: "Esquivel y Suárez de Urbina, Antonio María", en Enciclopedia del Museo del Prado. T III. Madrid, 2006, pp. 1011-1014; y PÉREZ CALERO, Gerardo: "Esquivel y Suárez de Urbina, Antonio María", en Todo el Prado. Madrid, 2012, p. 216.

${ }^{3}$ GUERRERO LOVILlO, José: Antonio María Esquivel. Madrid, 1957, p. 15.

${ }^{4}$ Precisamente cuando actuó como testigo de la boda de su amigo, celebrada justamente el mismo año, se le domiciliaba como vecino de esta collación. Véase RUBIO JIMÉNEZ, J.: José María Domínguez Bécquer. Sevilla, 2007, p. 28. 
demandado por las sociedades sevillana y madrileña, como por una simple necesidad de subsistencia ${ }^{5}$.

Dada esta exigencia vital que decimos, pronto encararía el retrato como género preferente en su producción artística, que le permitiría, no tanto adentrarse en las estéticas murillista y nazarena, que practicaría al alimón en sus cuadros históricos y religiosos ${ }^{6}$, cuanto a mantener los convencionalismos estéticos del romanticismo tan comunes en la Sevilla de José María Domínguez Bécquer y en la corte con Federico de Madrazo a la cabeza.

Ciertamente los retratos de Esquivel pintados en Sevilla, como los de su mujer que nos ocuparán después, tienen la impronta propia de los pintores románticos locales sobre todo de su citado amigo y maestro. Tanto es así que, siguiendo a este -al poco de casarse en 1827, y del que fue también testigo de boda, retrató a su esposa Joaquina Bastida (Museo de Bellas Artes de Sevilla)-, Antonio María haría lo propio el mismo año y con idéntica edad al retratar a la suya Antonia Rivas recién desposada. Sin embargo, es evidente la diferencia entre ambos: más atrevida la pose de la modelo de José María y algo convencional aunque más atractiva la de Antonio María.

El retrato de Antonia Rivas, cronológicamente el primero de los dos que ahora nos ocupan, hoy en una colección particular extremeña, es un óleo sobre lienzo de 102 x $82 \mathrm{~cm}$, en cuyo ángulo inferior izquierdo puede leerse "A. Esquivel. f. Sevilla en 1828" (Figuras 1-2).

Al interés fisonómico y emotivo que manifiesta la modelo se une el estético, toda vez que la obra corresponde a los inicios de la serie de retratos ejecutados en Sevilla por un entonces joven pintor al que aún quedaba una larga y triunfal carrera por recorrer.

Como decíamos, la obra mantiene en general los convencionalismos propios del tipo de retrato protorromántico común en la escuela sevillana, sin embargo acusa también ciertos resabios de la moda femenina "Estilo imperio" o "Regency style" aún subsistente en España durante los últimos años fernandinos procedente de Europa, Francia e Inglaterra, sobre todo, caracterizada entre otros pormenores por el uso del vestido de "mangas globo" o "mangas balón"7 (Figura 3).

Posee tamaño académico y formato vertical. La modelo, de tres cuartos y posición sedente, mira frontalmente al espectador al que parece dirigirse de manera

${ }^{5}$ Hay quienes elevan a más de trescientos los retratos ejecutados por el artista. Vid. DE LA BANDA Y VARGAS, Antonio: Antonio María Esquivel, op. cit., p. 95.

${ }^{6}$ PÉREZ CALERO, Gerardo: "Consideraciones estéticas en torno a la obra del pintor Antonio M. Esquivel”, Laboratorio de Arte, 24, 2012, pp. 527-535.

${ }^{7}$ Debemos considerar a este respecto cómo la escuela gaditana de pintura acepta esta moda en retratistas como Manuel Montano (1770-1846), quien refleja tal estilo en la copia del Autorretrato de Angelika Kauffmann (1741-1807), o la que luce la pintora Victoria Martín (1794-1869) en el suyo propio. Ambos en el Museo de Cádiz. 
sencilla y convincente manejando las manos con naturalidad. Viste un sencillo traje de tonalidad miel, mangas abullonadas y escote en barco, sostiene el abanico con su mano diestra mientras coloca en elegante ademán la contraria, luce collar y colgante de coral y oro, pendientes con doble camafeo y oro a la moda imperio, y se peina como buena andaluza con flores sobre el cabello recogido y peineta de carey (Figuras 4-5).

Si la iconografía de la obra responde a los parámetros estéticos ya citados, en su lectura iconológica encontramos una intencionalidad marcadamente erótica vinculada a lo afectivo y sentimental propia de un joven y feliz matrimonio que espera consumar su nueva situación conyugal. Para ello, la flamante esposa maneja las manos con elocuente simbolismo femenino, de tal modo que si el abanico sostenido firmemente por Antonia se afirma en su muslo derecho queriendo expresar cierto tono irónico con resistencia a ser poseída, al propio tiempo la mano contraria acepta la entrega a su marido en un ficticio toma y daca con mirada complaciente (Figuras 6-7).

Tenemos noticia de que en torno a la fecha de su matrimonio, Esquivel se autorretrató en un óleo sobre lienzo de menor formato acompañado de su joven esposa y con los útiles de pintar $^{8}$. Por otra parte, recientemente hemos localizado en el mercado madrileño un segundo retrato ejecutado por Esquivel a su esposa en 1831, ya madre de Carlos María y recién llegados los tres a Madrid 9.

En esta ocasión Antonia Rivas es retratada de busto, mirando fijamente al espectador e inscrita en un óvalo, como hicieran antaño algunos pintores barrocos sevillanos y también hogaño su amigo y compañero José Gutiérrez de la Vega ${ }^{10}$. En tan poco tiempo, la fisonomía de la joven esposa ha cambiado notablemente por su reciente maternidad. Ahora más gruesa, lo que se evidencia en el rostro de sonrosados y prominentes pómulos. También su nuevo estatus la obliga a variar el tono de su vestimenta: poco ha, más clara, ahora más oscura, de talle alto, hombros descubiertos y se ciñe con ancho cinturón. Luce collar y pendientes de coral. Su hermosa y negra cabellera se compone de anchos tirabuzones, remata la cabeza con discretas flores al modo sevillano (Figura 8).

Con posterioridad, el pintor retrató de nuevo a su consorte en varias ocasiones y en cuadros de mayor formato siendo ya madre de sus últimos hijos, Vicente

${ }^{8}$ Según Guerrero Lovillo, la obra se hallaba en la colección del marqués de Aracena, hoy sin localizar. GUERRERO LOVILLO, José: Antonio María Esquivel, op. cit., p. 32. Citado también en DE LA BANDA Y VARGAS, Antonio: Antonio María Esquivel, op. cit., pp. 99-100, que informa de las medidas: 0,47 x 0,45 cm.

9 Se trata de un óleo sobre lienzo, titulado Retrato de dama, de 55 x $42 \mathrm{~cm}$. Firmado en Madrid en 1831. En el mercado madrileño en octubre de 2018.

${ }^{10}$ Vid. ARIAS DE COSSIO, Ana María: José Gutiérrez de la Vega. Pintor romántico sevillano. Madrid, 1978. 
e Isabel, con alguno de los cuales aparece acompañada aunque más con la menor en actitud protectora (ejemplares del Museo de Bellas Artes de Sevilla).

A diferencia de los que ahora nos ocupan, los retratos de Esquivel hechos en la Villa y Corte seguirán más de cerca la iconografía propia de la moda cortesana de su tiempo. Los gestos y las actitudes de los ejecutados entonces a su esposa, ya representada como distinguida dama de la sociedad madrileña, adquirirán otro talante, y su expresión responderá a una nueva situación de serenidad, seguridad y confianza como consecuencia del ascenso social de su marido en la cumbre de su carrera artística.

Fecha de recepción: 29 de octubre de 2018

Fecha de aceptación: 11 de febrero de 2019 


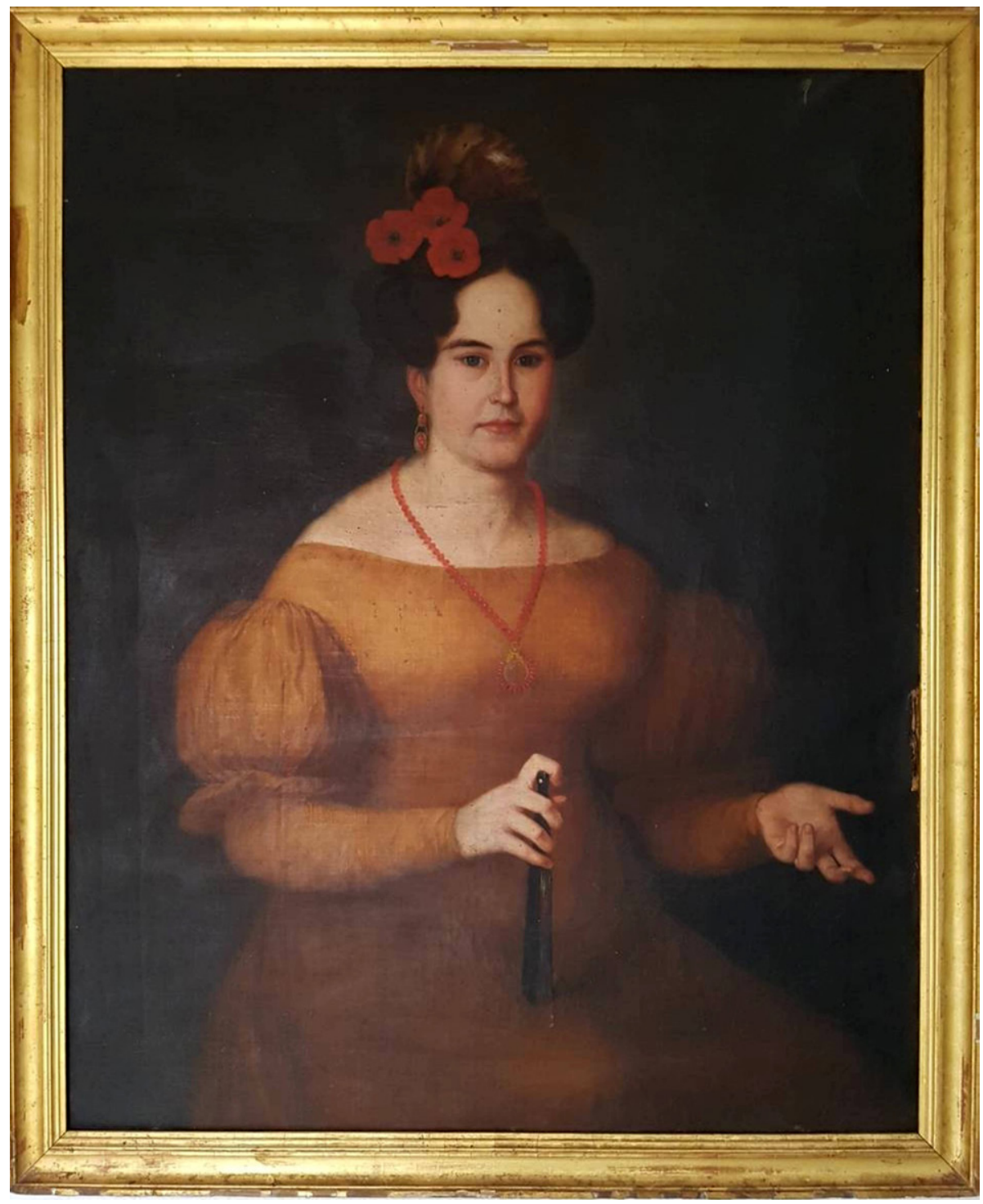

Figura 1. Antonio María Esquivel, Retrato de su mujer, Sevilla, 1828, propiedad particular. 
Figura 2. Antonio María Esquivel, Retrato de su mujer, Sevilla, 1828, propiedad particular. Firma: "A. Esquivel. f. Sevilla en 1828".

Figura 3. Antonio María Esquivel, Retrato de su mujer, Sevilla, 1828, propiedad particular. Detalle de una manga.
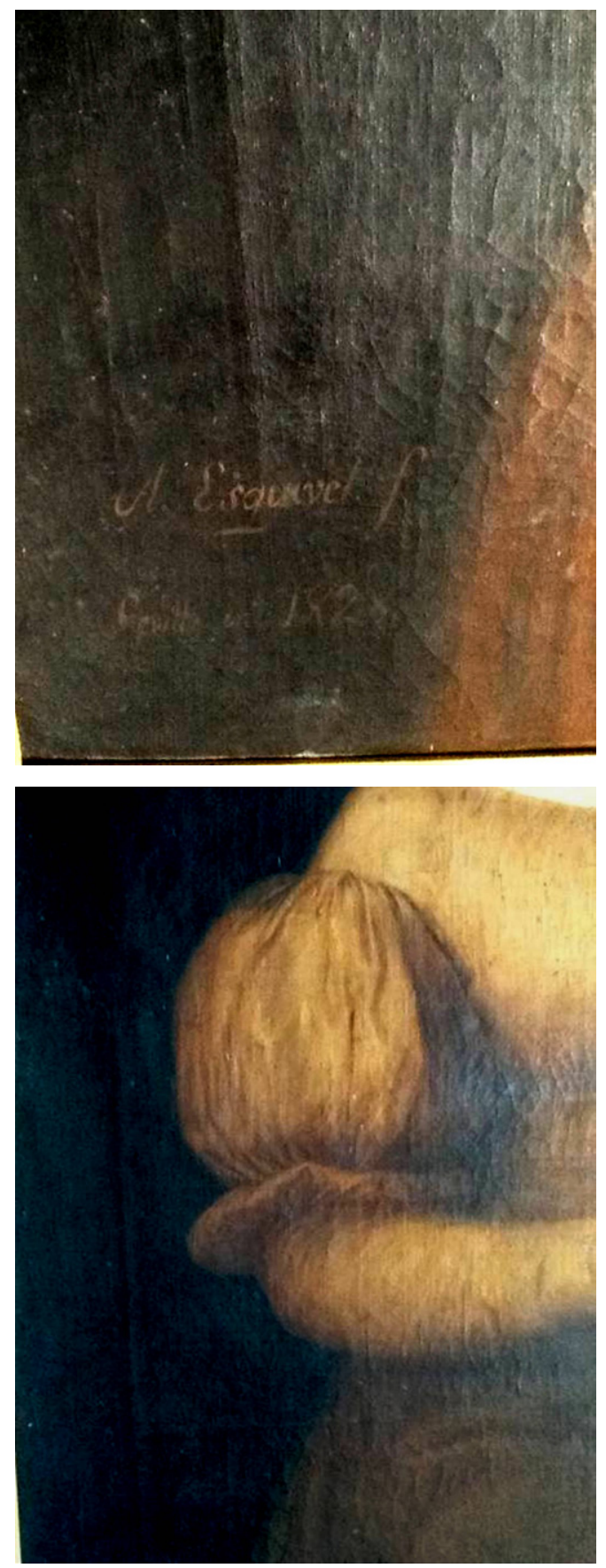

LABORATORIO DE ARTE 31 (2019), pp. 683-692, ISSN 1130-5762 e-ISSN 2253-8305 - DOI http://dx.doi.org/10.12795/LA.2019.i31.42 


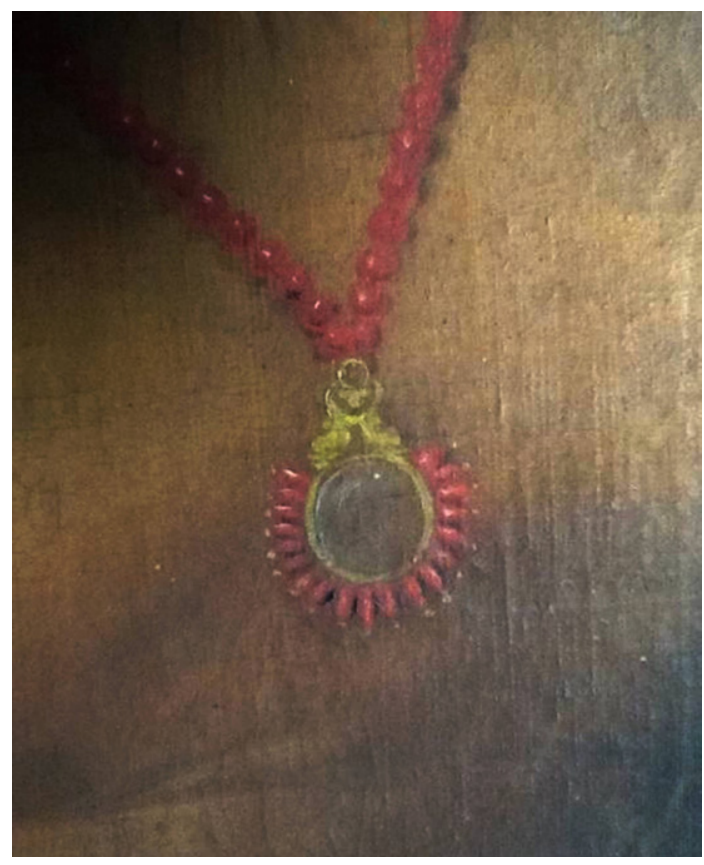

Figura 4. Antonio María Esquivel, Retrato de su mujer, Sevilla, 1828, propiedad particular. Detalle del colgante.

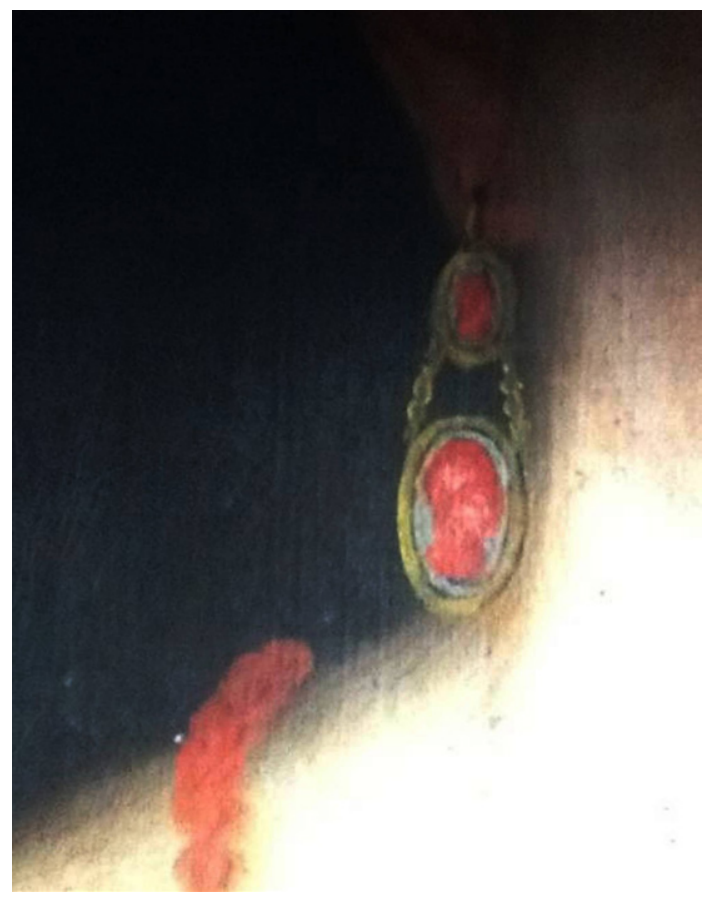

Figura 5. Antonio María Esquivel, Retrato de su mujer, Sevilla, 1828, propiedad particular. Detalle del pendiente.

LABORATORIO DE ARTE 31 (2019), pp. 683-692, ISSN 1130-5762

e-ISSN 2253-8305 - DOI http://dx.doi.org/10.12795/LA.2019.i31.42 
Figuras 6 y 7. Antonio María Esquivel, Retrato de su mujer, Sevilla, 1828, propiedad particular. Detalle de las manos.
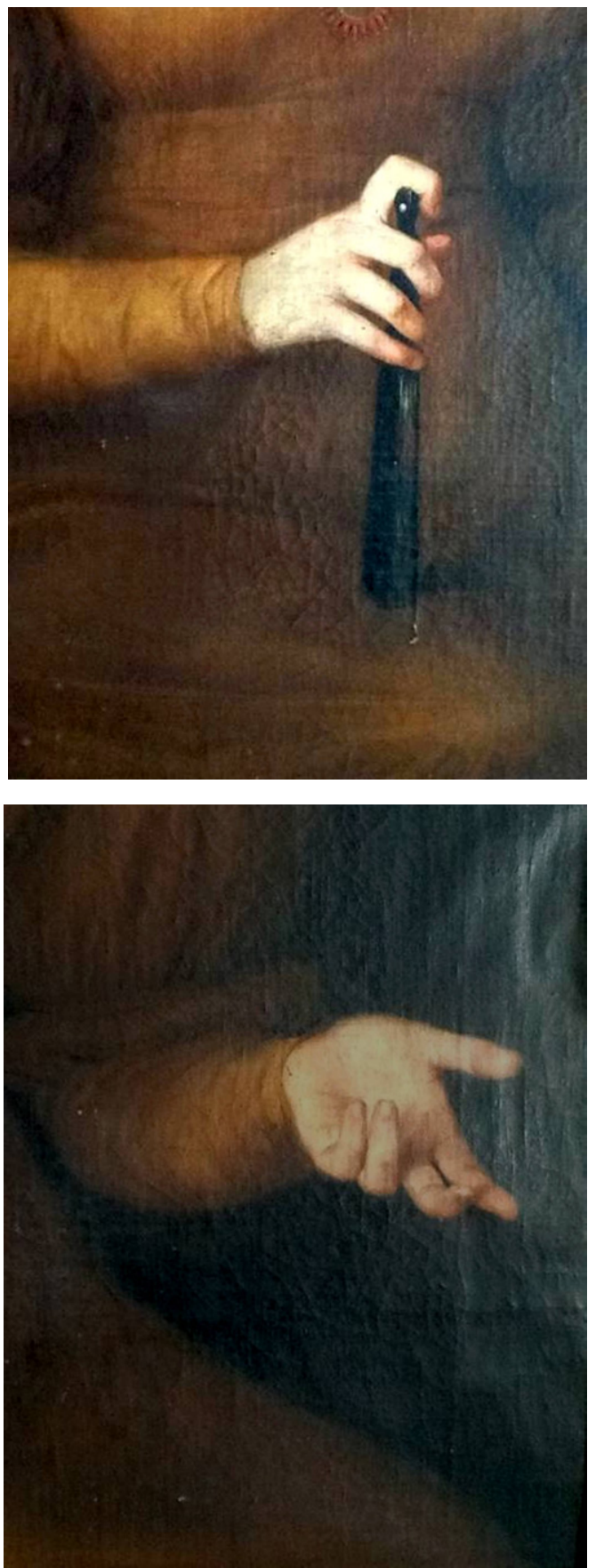

LABORATORIO DE ARTE 31 (2019), pp. 683-692, ISSN 1130-5762 e-ISSN 2253-8305 - DOI http://dx.doi.org/10.12795/LA.2019.i31.42 


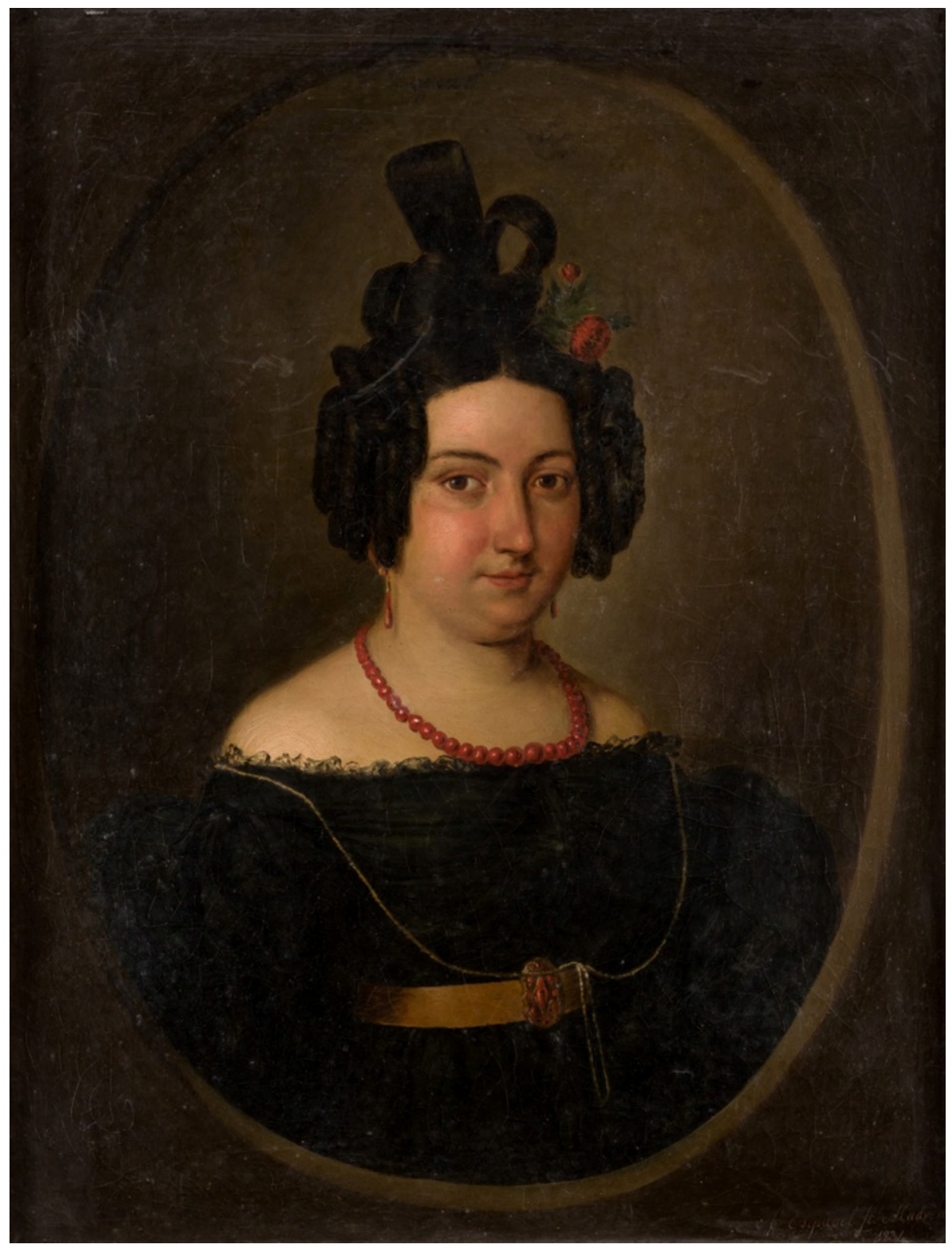

Figura 8. Antonio María Esquivel, Retrato de su mujer, Madrid, 1831, en el mercado madrileño en octubre de 2018. 